\title{
Elucidating Specificity Opens a Window to the Complexity of Both the Innate and Adaptive Immune Systems
}

\author{
Gabrielle T. Belz ${ }^{1-3}$
}

\begin{abstract}
Science is a tedious and painstaking business. Many discoveries are considered incremental, individually not necessarily earth shattering, but collectively providing the critical broad framework on which pivotal insights can emerge. Transformational discoveries spring from this knowledge legacy of others and spur a fervent discovery process, often driven by technological developments. The seminal discovery of major histocompatibility class restriction I (MHCI) and its role in antiviral infections by Doherty and Zinkernagel in 1974 was one such discovery - the key that unlocked the treasure chest to the rich tapestry of the diversity of the immune system. An army of researchers have teased apart the different elements of the immune response, which now brings us to a deeper understanding of immune memory and protective immunity. In this process, it has uncovered a multitude of cell types that bridge the innate and adaptive arms of the immune system-blurring the line between these two branches - and ultimately fortifying the development of long-term immune protection.
\end{abstract}

Keywords: MHCI, viral infections, cell types, T cell memory, immune protection

\section{Classical Frameworks Blurred by Discoveries}

$\mathbf{T}$ He IMMUNE SYSTEM protects the body against foreign invaders. It draws together the evolutionary ancient "innate" immune response and the "modern" adaptive response, which for many years have been largely viewed and explored as two distinctly separate, but complementary, strands in immunology. The innate arm is considered universal-it lacks antigen-specific receptors, but can be rapidly mobilized to attack a potential invader by almost immediate induction of an armory of effector functions in the innate immune cells. In contrast, the adaptive system is marked by exquisite specificity in antigen recognition and with this comes the ability to generate immune "memory." Immune memory uniquely ensures that the body has longlived protection. It depends on rewiring of the cellular genomic machinery found in naive cells to generate highaffinity antigen-specific B and T cells that become "poised" in their capacity to rapidly induce effector molecules similar to innate cells, a feature we endeavor to take advantage of for vaccination. Discoveries set in motion over the past 100 years, however, have blurred the line between the sharply defined functions of the innate and adaptive immune systems, opening up a rich world of connections between these arms, which we are now just beginning to unravel.

\section{Major Histocompatibility Complex Class I Restriction: The Secret to Tuning the Immune System's Levers}

The notion of immune specificity had been appreciated for some time. Nevertheless, the earliest immunologists Ehrlich (1878) (26) and Metchnikoff (1892) (51) sat on opposite sides of the divide on the topic of how specificity and the properties of immune memory might be imparted, and despite extensive speculation and heated debate, it has remained elusive (Fig. 1).* Indeed, it is only in the last 50 years, facilitated by many technical advances, that the field has started to unravel the fundamental characteristics of immune cells that define memory and the protective functions that finely tune immune responses after encounters with antigens and foreign organisms.

Gorer, an early pioneer in transplant immunology, observed in cancer studies that tumors failed to grow when transplanted into genetically disparate hosts (31). Through this observation, he helped discover the murine major

*http://www.nobelprize.org/prizes/medicine/1908/summary

\footnotetext{
${ }^{1}$ The University of Queensland Diamantina Institute, Brisbane, Australia.

${ }^{2}$ Walter and Eliza Hall Institute of Medical Research, Melbourne, Australia.

${ }^{3}$ Department of Medial Biology, University of Melbourne, Melbourne, Australia.

(C) Gabrielle T. Belz 2020; Published by Mary Ann Liebert, Inc. This Open Access article is distributed under the terms of the Creative Commons Attribution Noncommercial License (http://creativecommons.org/licenses/by-nc/4.0/) which permits any noncommercial use, distribution, and reproduction in any medium, provided the original author(s) and the source are cited.
} 


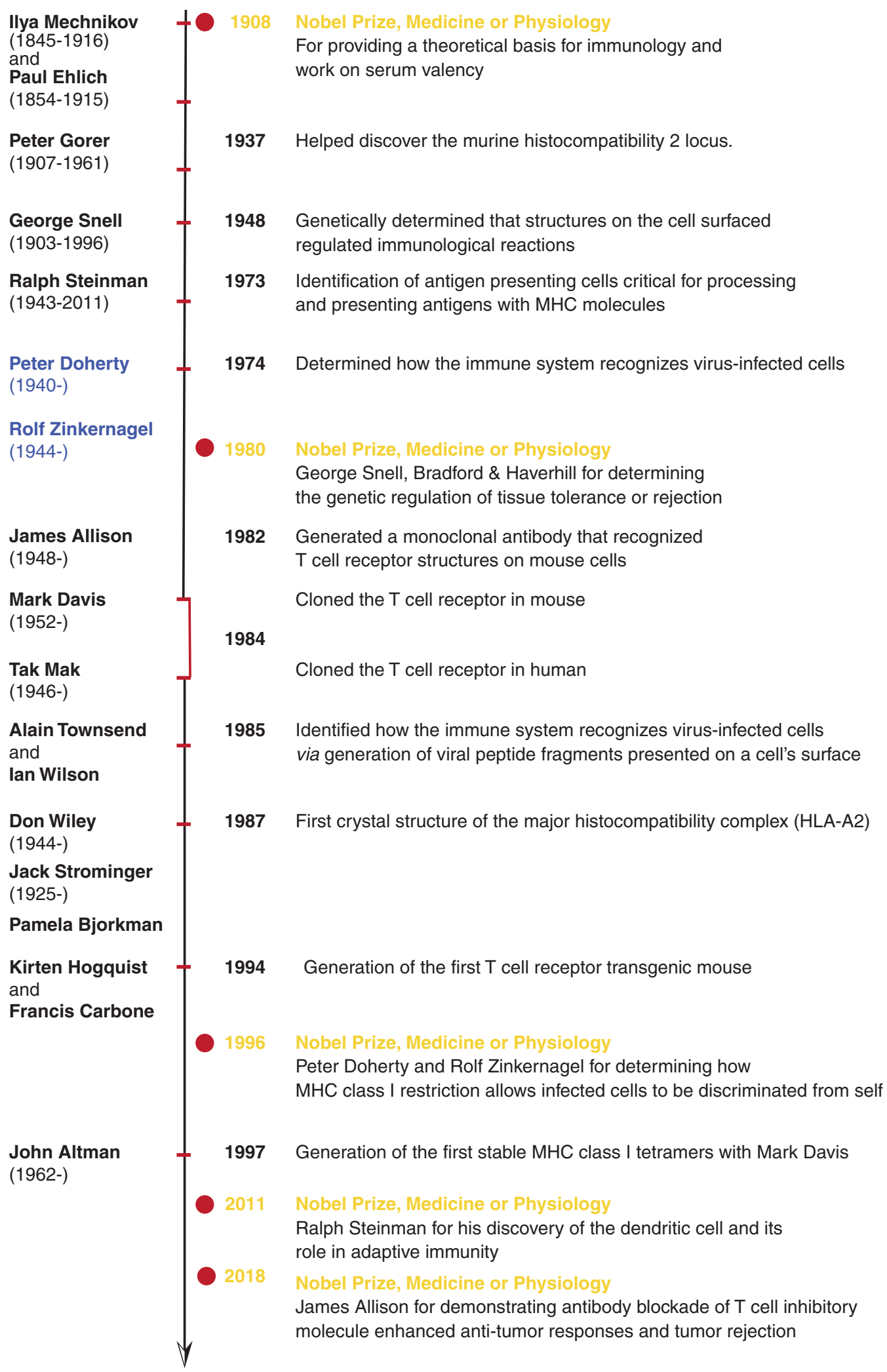

FIG. 1. Timeline of key discoveries around MHC restriction and understanding specificity in the immune system. MHC, major histocompatibility complex. 
histocompatibility 2 locus, (or $\mathrm{H}-2$ ) which is analogous to the human leukocyte antigen. Snell $(66,67)$ together with Baruj Benacerraf and Jean Dausset concluded that it must be genetic factors that dictated whether a positive or negative outcome (so called "compatibility") would transpire after transplanting tissue between individuals. Compatible transplants would allow a graft to establish, while noncompatible transplants would result in enormous tissue damage and graft failure. This group was later awarded the Nobel Prize for Physiology or Medicine in 1980 (www.nobelprize.org/ prizes/medicine/1980/summary?). These discoveries were a key step forward in the transplantation field, but did not identify the mechanics of tissue rejection. This would wait until the unique combination of Doherty and Zinkernagal came together at the John Curtin School of Medical Research in Canberra, Australia, where together they stitched together the meaning of previous work and then performed the pivotal experiments that shed light on this complex problem. They determined that tissue damage or responses against a pathogen fundamentally required a $\mathrm{T}$ cell to simultaneously recognize a foreign antigen together with a self-protein of the major histocompatibility complex (MHC) expressed on the surface of antigen-presenting cells. It was this step that resulted in the induction of the destructive effector functions of the cytotoxic $\mathrm{T}$ cell to kill pathogeninfected cells $(81,82)$. Together Doherty and Zinkernagel shared the Nobel Prize in 1996 (www.nobelprize.org/prizes/ medicine/1996/summary). This discovery represented a pivotal turning point in unraveling the interactions that dictated specificity. Despite this, the outcomes of responses, especially antiviral responses depended on the broader enumeration of the number of $\mathrm{CD}^{+}$and $\mathrm{CD}^{+} \mathrm{T}$ cells. The individual specificity of a $\mathrm{T}$ cell was not known, or whether they were all specific, or so called "bystander cells" drawn into a response by the flood of cytokines in the inflammatory millieu. In fact, there was no technique that could allow detection of these antigen-specific T cells to understand exactly how the cells were programmed to even consider how they might be used either therapeutically or in strategic vaccine design. This remained a significant roadblock in progress.

\section{The Tetramer Revolution: Miscounting Reveals New Paradigms}

For more than a decade, Mark Davis together with several postdoctoral fellows, worked on this problem in an effort to integrate molecular and cellular aspects of $\mathrm{T}$ cell recognition. In 1996, Altman and Mark successfully generated the first stable MHC class I peptide tetramers and demonstrated for the first time, the ability to track antigen-specific $\mathrm{CD} 8^{+} \mathrm{T}$ cells (3). This was achieved by creating a monomer of the MHC class I heavy chain, $\beta 2 \mathrm{~m}$, into which a specific peptide could be folded, and then biotinylating the heavy chain tail to allow it to be conjugated with an avidin-labeled fluorochrome, thereby creating the multimeric soluble MHC class I-peptide tetramers. Combined with fluorescence-activated cell analyses, this tool could be used in a manner similar to an antibody to detect virus-specific cells. In the first study, these tetramers were used to map influenza and human immunodeficiency virus responses in man (3). Studies in mice followed very soon after with John Altman joining forces first with Ahmed (Emory Vaccine Center, Atlanta,
Georgia), and subsequently through a collaboration with Doherty and other researchers to launch frantic efforts to unravel "the numbers" on a variety of antiviral responses $(17,27,53)$. Before this transformational development, enumeration of antigen-specific $\mathrm{T}$ cells depended on extrapolating from chromium release assays and the "gold standard" for quantitation-the limiting dilution assay (LDA). The LDA combined cell purification with microculturing and ${ }^{51} \mathrm{Cr}$-labeling resulting in "mountains" of tissue culture plates that were read on a gamma counter $(2,73)$. Other experiments immediately preceding the tetramer technology involved restimulating cells with cognate peptides - this required prior knowledge of the pathogen or antigen-specific peptides-but allowed ELISPOT analyses or use with flow cytometry to map intracellular cytokine production from which calculations of $\mathrm{T}$ cell numbers could be made $(36,47,72)$. This latter approach became invaluable in driving peptide epitope mining to allow the subsequent development of tetramer reagents. It was cheap and could be relatively high-throughput at a time when the establishment of Tetramer Facilities was only just beginning.

Within a short period, an entire library of $\mathrm{CD} 8^{+}$tetramers were developed, but the technology was also extended to the more complex $\mathrm{CD}^{+}$tetramers $(20,24,64)$, which collectively allowed highly quantitative analyses of immune responses to be performed. In addition to the amazing utility of tetramers in being able to stain live cells directly from tissues, it also allowed comparisons of the different quantitation approaches to be performed against the more established techniques and to allow immunologists to fully characterize the numbers, distribution, function, and molecular wiring of $\mathrm{T}$ cells. Several of the findings that emerged from these studies challenged the prevailing understanding of the time.

\section{More than about dominance}

It had long been held that the cytotoxic T cell populations generated in response to viruses were directed toward a single immunodominant epitope, or at least, no more than a very small number of different $\mathrm{T}$ cell epitopes. However, the capacity to use mimotopes-large libraries of small quantities of peptides designed, based on the sequence template of a pathogen-together with tetramers revealed that pathogens encoded dozens peptides that could be recognized by $\mathrm{CD}^{+}$and $\mathrm{CD}^{+} \mathrm{T}$ cell populations although differing in abundance and effector molecule profile and all likely to play important roles in an antiviral response $(4,5,9,10,19,23,69,76,79)$. In addition, recent evidence indicates that most viral peptides displayed by MHC class I on infected cells are in fact immunogenic (21). Many factors dictate the efficient presentation of these peptides and subsequent amplification of different $\mathrm{T}$ cell specificities during an infection, but the vast library of peptides generated by the processing machinery of a cell are critical for optimizing the generation of different $\mathrm{T}$ cell populations through different modes of antigen presentation on different MHC haplotypes $(11,12,74)$. Despite this enormous progress in understanding the specificity of $\mathrm{T}$ cell populations and how they are generated, a key question remains in the field-is simply generating large populations of pathogen-specific $\mathrm{T}$ cells the ideal protective response or are smaller subdominant populations crucial in immune 
defense, particularly in chronic infections where evasion strategies against less abundant viral proteins may not be as strongly targeted.

\section{The first comprehensive catalog of $T$ cells everywhere}

In addition to beginning to understand the heterogeneity of $\mathrm{T}$ cell populations generated in an immune response, for the first time, immunologists could enumerate and catalog both $\mathrm{CD}^{+}$and $\mathrm{CD}^{+} \mathrm{T}$ cells across whole body responses in both lymphoid and nonlymphoid tissues. This allowed the development of a much clearer understanding of the dynamic regulation of cells in different tissue compartments, their trafficking behavior, and functional capability within their various niches $(48,49,57)$. Ultimately, this set the stage for probing $\mathrm{T}$ cell-lodged nonlymphoid tissues in much more detail. One might anticipate that some cells that were strategically located at barrier surfaces might be poised for more immediate responses, akin to innate cells, against infections. Indeed, such cells, now known as $\mathrm{CD}^{+}$tissueresident $\mathrm{T}$ cells $(28,29)$ were identified as were other populations of uncharacterized $\mathrm{T}$ cells such as $\mathrm{T}$ follicular helper cells, Tc17 cells, and unanticipated populations such as those that emerge in chronic infections that might be functionally reprogrammed to afford some protection, even in an apparently $\mathrm{T}$ cell exhaustion setting $(34,44)$.

\section{Reshaping how we view $C D 4^{+} T$ cell help}

$\mathrm{CD}^{+} \mathrm{T}$ cell help had long been held to be variably required for effective induction of an effective $\mathrm{CD}^{+} \mathrm{T}$ cell response. The trigger for their necessity depended on the degree of inflammation associated with an infection whereby very strong inflammation resulting in large amounts of cytokine being produced circumvented the contributions normally afforded by the helper $\mathrm{CD}^{+} \mathrm{T}$ cell subset. Reanalyses of the early experiments initially performed using LDA but now using MHC class I-tetramers and with a focus on understanding whether loss of CD4 T cell "help" might induce other previously unappreciated holes such as functional deficits showed otherwise. Tetramers allowed careful enumeration of the virus-specific cells at every stage of the $\mathrm{CD} 8^{+} \mathrm{T}$ cell response. It showed that surprisingly, $\mathrm{CD} 8{ }^{+} \mathrm{T}$ cells that did not "dance" with $\mathrm{CD}^{+} \mathrm{T}$ cells during the genesis of a response were only poorly armed and struggled to survive long term for recall into a secondary response, seriously impairing enduring protective memory $(8,50,71)$. This was perplexing, but cross-analyses with the LDA approach showed that shortterm in vitro expansion of $\mathrm{T}$ cells masked the overall failure of individual cells to survive resulting in the development of a model that did not fully reflect the development and outcome of a full-blown antiviral response in vivo. This reduced survival and impaired expansion of $\mathrm{CD}^{+} \mathrm{T}$ cells during the recall response appear to rely on the TNF- $\alpha$-related apoptosis inducing ligand (TRAIL), which fails to be properly regulated in the absence of $\mathrm{CD}^{+}$ $\mathrm{T}$ cell help $(6,35)$. Collectively, our appreciation for the critical cues provided by $\mathrm{CD}^{+}{ }^{+} \mathrm{T}$ cells at the earliest stages of an infection has radically changed and this has had a major impact on how we view of the "ingredients" necessary to design effective vaccines.

\section{Immunological accounting-much more than we expected}

That ability to apply a quantitative analysis to antigenspecific $\mathrm{T}$ cells revealed that we could not fully account for all the $\mathrm{T}$ cells or other immune cells in general if the tetramer numbers were simply defined by our current models and knowledge. Had we missed something-were there populations of immune cells that we had not yet discovered? This was fuelled by the more widespread application of genomics to the analyses of $\mathrm{T}$ cells-either through individual cell analyses or tracking approaches. Genomics has revolutionized our understanding of how not only $\mathrm{T}$ cell receptors are put together but also B cell receptors-particularly the diversity in selection of alpha and beta chains encoding public and private specificities that enable them to recognize linear and conformational viral epitopes. In addition, various cell tracking methods were developed to stain cells ex vivo and adoptively transfer them back into hosts (e.g., carboxyfluorescein diacetate succinimidyl ester [CFSE] labeling together with $\mathrm{T}$ cell receptor transgenic mice) $(46,52,58,68)$ and mice encoding "master" transcription factors linked to fluorescent markers to enable the behavior and history of cells to be tracked in vivo. The premise of the latter was that a particular factor was largely, if not completely, restricted to an individual $\mathrm{T}$ cell type or stage. However, it began to emerge that this was not necessarily the case and that other T cells and immune cells also expressed such markers providing clues to a much broader repertoire of cells involved in immune protection.

\section{Nonconventional T Cells-Bridging the Adaptive-Innate Divide}

A vast variety of antigens exist in the environment. The immune responses typically focused on by the research community mapped to our conventional understanding that $\mathrm{T}$ cell epitopes, especially $\mathrm{CD}^{+} \mathrm{T}$ cell epitopes, are linear peptides that bind into the MHC class I or class II groves delineated by two $\alpha$-helices overlying and eight antiparallel $\beta$-strands, but differing on whether the grooves are open or closed (41). Linear epitopes provide a simple model, but does not account for a large number of antigens that had much more complex structures (e.g., complex glycoproteins) creating a major gap in our overall understanding of the dynamic and broad recognition process in immunity. It was appreciated, however, that large populations of "nonconventional" $T$ cells could be found in immune responses. These often accumulated in mucosal sites and they could recognize nonpeptide antigens presented by specialized MHC class I-like molecules. These T cells included CD1restricted $\mathrm{T}$ cells, MR1-restricted mucosal-associated invariant T cells (MAIT cells), MHC class Ib-reactive T cells, and $\gamma \delta \mathrm{T}$ cells which could recognize lipids, small-molecule metabolites, and modified peptides, some of which could be derived from pathogens $(30,62)$. Examples of these are MHC class Ib-reactive $\mathrm{T}$ cells that are necessary in multiple infections, including herpesvirus (15) and Listeria infection $(16,43,55)$; and MAIT cells that are restricted to the nonpolymorphic MHC class I-like protein MR1, a $\beta 2$-microglobulin-associated antigen-presenting molecule $(32,59,75)$. Tetramers are now available to allow the comprehensive mapping of these very different types of cells 
revealing, for example, that MAIT cells are a highly represented population in humans. Now, the focus is to elucidate how they work in concert with classical adaptive immune cells to afford protection.

\section{Innate Cells Share Key Features of Adaptive Immune Cells in Defense and Protection}

Due to the specificity of their receptors and their capacity to develop high potency "mature" receptors and a genomic architecture endowing them with a heightened ability to respond to reencounter with a pathogen, $\mathrm{B}$ cells and $\mathrm{T}$ cells have long been held as the keepers of the enduring protective memory response (Fig. 2). Immunological memory has been viewed as a defining feature of the adaptive immune system. These hallmarks of memory include (a) high proliferative potential or clonal expansion, (b) the ability to rapidly generate effector cells while maintaining a memory cohort and thus "memory-enabled" cells that exhibit multipotency, and (c) the ability to self-renew through signals provided by the cytokines IL-7 and IL-15 that drive homeostatic turnover. It is now clearer that a subset of naive $\mathrm{T}$ cells preferentially give rise to the memory cohort and these can be detected within the first few days of an infection (22,33,37-39,56), but also that effector $\mathrm{CD}^{+} \mathrm{T}$ cells can be "rewired" to form memory cells (80). The emergence of this memory population is associated with the development of epigenetic modifications that allow a cell to essentially "fix" or "bookmark" gene expression patterns enabling rapid access to the cellular response machinery and induction of effector molecules $(1,80)$. The ability to isolate antigen-specific $\mathrm{T}$ cells at specific stages of development in response to antigens has greatly facilitated teasing apart the molecular program that regulates the formation of different classes of these cells. It has also enabled comparison with innate lineages to demonstrate that the switches that impart "effector" and "memory" traits are not restricted solely to adaptive immune cells (42) (Fig. 2).

\section{Memory is not just for $T$ cells}

Innate immune cells exhibit two distinct features that strongly parallel $\mathrm{T}$ cell development-memory and plasticity (Fig. 2, Table 1). This is perhaps best highlighted by natural killer (NK) cells, in which murine cytomegalovirus (MCMV) preferentially activates the receptor Ly49H. Ly49H binds the MCMV-encoded glycoprotein m157 to drive clonal expansion and contraction of NK cells, resulting in the formation of a long-lived memory pool that can be recalled into a subsequent challenge $(14,42,70)$. NK cell populations, similar to adaptive immune cells, can be amplified through a multisignal model using a combination of

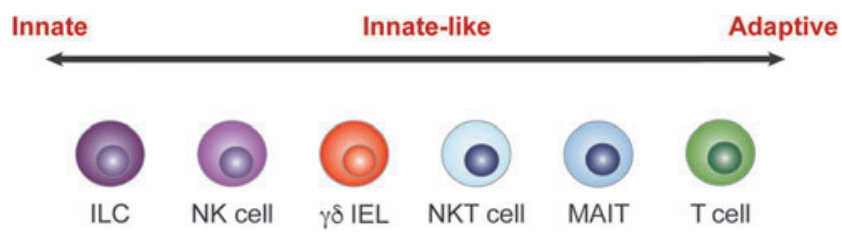

FIG. 2. Characteristics of immune cells in protective responses.

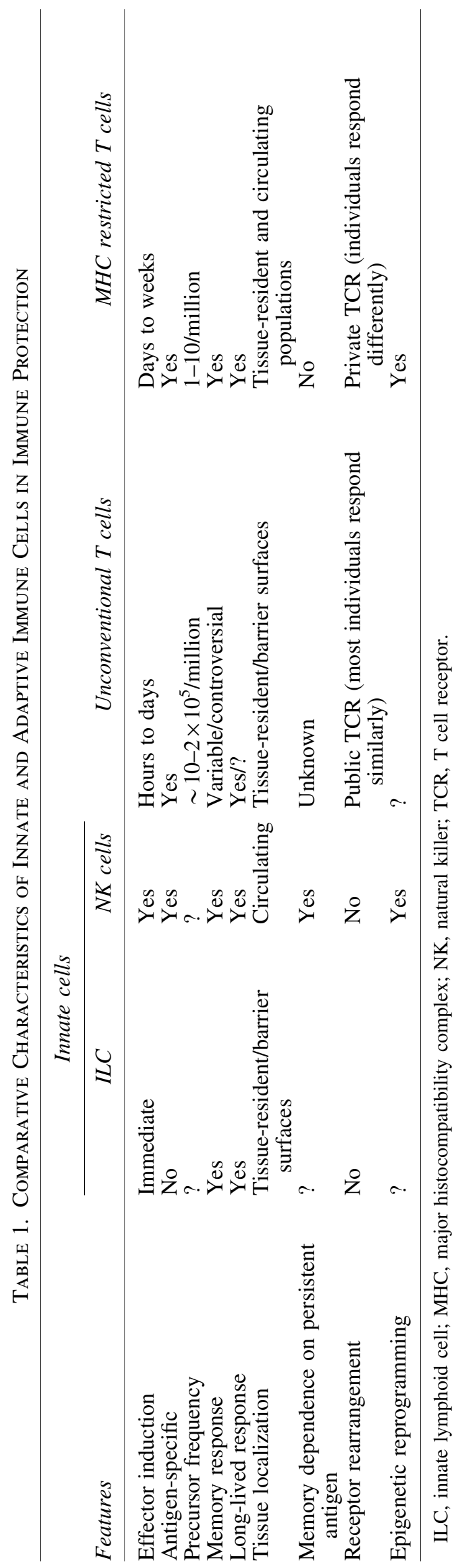


antigen recognition through activating receptors (signal 1), accessory molecules such as DNAM-1 (DNAX Accessory Molecule-1 or CD226) (signal 2, costimulation), and inflammation via cytokine stimulation (signal 3) that results in chromatin changes akin to T cell modifications (42). Cytokines alone are sufficient to drive expansion of NK cell populations, however, this antigen-independent pathway does not result in enduring persistence of the NK cells in contrast to that observed for antigen-dependent NK cell responses. Thus, cytokines result in poorly sustained memory responses. To what extent other innate and nonconventional lymphocytes also exhibit long-lived memory properties remains unclear. However, these observations highlight the opportunity to target lineages other than $\mathrm{T}$ cells in driving immune protection and therapy and to think more broadly about what comprises immune memory.

\section{Plasticity enables dynamic responses}

Plasticity is a characteristic which is most notably associated with $\mathrm{CD}^{+}{ }^{+} \mathrm{T}$ cells, which can differentiate and acquire distinct functions to combat pathogens but can adapt and fine tune their effector functions to the specific cellular cues of the infection (25). These changes are programmed within a framework of cytosolic signaling, metabolic and epigenetic circuitry that establishes and stabilizes $\mathrm{T}$ cell identity. Innate lymphoid cells (ILCs), a relatively recently discovered family of cells, strongly parallel $\mathrm{CD}^{+} \mathrm{T}$ cell subsets in their functional attributes (77). ILCs can, like $\mathrm{CD}^{+} \mathrm{T}$ cells, exhibit significant plasticity following their differentiation into their canonical group 1,2, and 3 subsets $(7,18,40,54,61,63,65,78)$. Although specific ILCs exhibit distinct subgroups and are enriched in different tissue microenvironments, they are functionally plastic in the presence of appropriate cytokine stimuli and can thus mimic features of other ILC subsets [e.g., ILC3 $\rightarrow$ ILC1-like cells under IL-12 or IL-15 stimulation $(13,18,78)$; ILC1 $\rightarrow$ ILC3 via IL-23 stimulation in humans (18); and ILC2 $\rightarrow$ ILC1-like cells $(45,54,65)]$. A commonality to each of these transitions is the ability of ILC to be enabled to secrete IFN- $\gamma$ and afford enhanced protection during disease control. Thus, ILCs situated predominantly at the body's surfaces parallel $\mathrm{CD}^{+} \mathrm{T}$ cell behavior and exhibit enormous flexibility in calibrating their responses to effectively ward off foreign invaders.

\section{Essential and Redundant Roles of Innate and Adaptive Cells in Immune Responses}

The capacity to elucidate the complex mechanisms regulated by MHC class I restriction, and to subsequently map individual antigen-specific cells involved in that recognition process, has been instrumental in unraveling the much larger spectrum of cells that bridge the innate-adaptive divide and ultimately affords immune protection. It is now clear that differences in the rapidity of a response to an insult and immune cell location are key features in defining the temporal engagement of innate and adaptive immune cells and the orchestration of their functional programs (60). However, studies over the recent years in teasing apart the complex tapestry of the system have revealed it as multilayered with parallel and complementary checkpoints between the innate and adaptive systems, opening a richness and complexity that have not previously been appreciated. These developments have been somewhat unexpected but coincide with major developments in the genomics and multiomics. They build on seminal findings in understanding immune recognition and specificity and will enable the field to establish where and when different immune cells contribute to protective responses with unprecedented resolution and to translate these findings into tangible therapeutic benefits.

\section{Author Disclosure Statement}

No competing financial interests exist.

\section{Funding Information}

Financial support for this work was provided by National Health and Medical Research Council (NHMRC) of Australia grant (APP1135898).

\section{References}

1. Akondy RS, Fitch M, Edupuganti S, et al. Origin and differentiation of human memory CD8 T cells after vaccination. Nature 2017;552:362-367.

2. Allouche M, Owen JA, and Doherty PC. Limit-dilution analysis of weak influenza-immune $\mathrm{T}$ cell responses associated with $\mathrm{H}-2 \mathrm{~Kb}$ and H-2Db. J Immunol 1982;129:689-693.

3. Altman JD, Moss PA, Goulder PJ, et al. Phenotypic analysis of antigen-specific T lymphocytes. Science 1996;274:94-96.

4. Anderson RW, Bennink JR, Yewdell JW, et al. Influenza basic polymerase 2 peptides are recognized by influenza nucleoprotein-specific cytotoxic T lymphocytes. Mol Immunol 1992;29:1089-1096.

5. Andreansky SS, Stambas J, Thomas PG, et al. Consequences of immunodominant epitope deletion for minor influenza virus-specific CD8+-T-cell responses. J Virol 2005;79:4329-4339.

6. Badovinac VP, and Harty JT. Programming, demarcating, and manipulating CD8+ T-cell memory. Immunol Rev 2006;211:67-80.

7. Bal SM, Bernink JH, Nagasawa M, et al. IL-1beta, IL-4 and IL-12 control the fate of group 2 innate lymphoid cells in human airway inflammation in the lungs. Nat Immunol 2016;17:636-645.

8. Belz GT, Wodarz D, Diaz G, et al. Compromised influenza virus-specific CD8(+)-T-cell memory in CD4(+)-T-celldeficient mice. J Virol 2002;76:12388-12393.

9. Belz GT, Xie W, Altman JD, et al. A previously unrecognized $\mathrm{H}-2 \mathrm{D}(\mathrm{b})$-restricted peptide prominent in the primary influenza A virus-specific CD8(+) T-cell response is much less apparent following secondary challenge. J Virol 2000;74:3486-3493.

10. Belz GT, Xie W, and Doherty PC. Diversity of epitope and cytokine profiles for primary and secondary influenza a virus-specific CD8+ T cell responses. J Immunol 2001;166: 4627-4633.

11. Bennink JR, and Yewdell JW. Murine cytotoxic T lymphocyte recognition of individual influenza virus proteins. High frequency of nonresponder MHC class I alleles. J Exp Med 1988;168:1935-1939.

12. Bennink JR, Yewdell JW, Smith GL, et al. Anti-influenza virus cytotoxic $\mathrm{T}$ lymphocytes recognize the three viral polymerases and a nonstructural protein: responsiveness to individual viral antigens is major histocompatibility complex controlled. J Virol 1987;61:1098-1102. 
13. Bernink JH, Krabbendam L, Germar K, et al. Interleukin12 and -23 control plasticity of $\mathrm{CD} 127(+)$ group 1 and group 3 innate lymphoid cells in the intestinal lamina propria. Immunity 2015;43:146-160.

14. Bezman NA, Kim CC, Sun JC, et al. Molecular definition of the identity and activation of natural killer cells. Nat Immunol 2012;13:1000-1009.

15. Boname JM, de Lima BD, Lehner PJ, et al. Viral degradation of the MHC class I peptide loading complex. Immunity 2004;20:305-317.

16. Bouwer HG, Bai A, Forman J, et al. Listeria monocytogenes-infected hepatocytes are targets of major histocompatibility complex class Ib-restricted antilisterial cytotoxic T lymphocytes. Infect Immun 1998;66:28142817.

17. Butz EA, and Bevan MJ. Massive expansion of antigenspecific CD8+ T cells during an acute virus infection. Immunity 1998;8:167-175.

18. Cella M, Otero K, and Colonna M. Expansion of human NK-22 cells with IL-7, IL-2, and IL-1beta reveals intrinsic functional plasticity. Proc Natl Acad Sci U S A 2010;107: 10961-10966.

19. Chen W, Calvo PA, Malide D, et al. A novel influenza A virus mitochondrial protein that induces cell death. Nat Med 2001;7:1306-1312.

20. Chu HH, Moon JJ, Takada K, et al. Positive selection optimizes the number and function of MHCII-restricted CD4+ $\mathrm{T}$ cell clones in the naive polyclonal repertoire. Proc Natl Acad Sci U S A 2009;106:11241-11245.

21. Croft NP, Smith SA, Pickering J, et al. Most viral peptides displayed by class I MHC on infected cells are immunogenic. Proc Natl Acad Sci U S A 2019;116:3112-3117.

22. Croom HA, Denton AE, Valkenburg SA, et al. Memory precursor phenotype of CD8+ T cells reflects early antigenic experience rather than memory numbers in a model of localized acute influenza infection. Eur J Immunol 2011; 41:682-693.

23. Crowe SR, Miller SC, Brown DM, et al. Uneven distribution of MHC class II epitopes within the influenza virus. Vaccine 2006;24:457-467.

24. Day CL, Seth NP, Lucas M, et al. Ex vivo analysis of human memory CD4 $\mathrm{T}$ cells specific for hepatitis $\mathrm{C}$ virus using MHC class II tetramers. J Clin Invest 2003;112:831-842.

25. DuPage $M$, and Bluestone JA. Harnessing the plasticity of CD4(+) T cells to treat immune-mediated disease. Nat Rev Immunol 2016;16:149-163.

26. Ehrlich P. Contributions to the Theory and Practice of Histological Staining [in German]. Leipzig, Germany: University of Leipzig, 1878.

27. Flynn KJ, Belz GT, Altman JD, et al. Virus-specific CD8+ $\mathrm{T}$ cells in primary and secondary influenza pneumonia. Immunity 1998;8:683-691.

28. Gebhardt T, Wakim LM, Eidsmo L, et al. Memory T cells in nonlymphoid tissue that provide enhanced local immunity during infection with herpes simplex virus. Nat Immunol 2009;10:524-530.

29. Gebhardt T, Whitney PG, Zaid A, et al. Different patterns of peripheral migration by memory CD4+ and CD8+ T cells. Nature 2011;477:216-219.

30. Godfrey DI, Uldrich AP, McCluskey J, et al. The burgeoning family of unconventional $\mathrm{T}$ cells. Nat Immunol 2015;16:1114-1123.

31. Gorer PA. The genetic and antigenic basis of tumour transplantation. J Pathol Bacteriol 1937;44:691-697.
32. Hashimoto K, Hirai M, and Kurosawa Y. A gene outside the human MHC related to classical HLA class I genes. Science 1995;269:693-695.

33. Huster KM, Busch V, Schiemann M, et al. Selective expression of IL-7 receptor on memory $\mathrm{T}$ cells identifies early CD40L-dependent generation of distinct CD8+ memory T cell subsets. Proc Natl Acad Sci U S A 2004;101:5610-5615.

34. Im SJ, Hashimoto M, Gerner MY, et al. Defining CD8+ T cells that provide the proliferative burst after PD-1 therapy. Nature 2016;537:417-421.

35. Janssen EM, Droin NM, Lemmens EE, et al. CD4 + T-cell help controls CD8 + T-cell memory via TRAIL-mediated activation-induced cell death. Nature 2005;434:88-93.

36. Jung T, Schauer U, Heusser C, et al. Detection of intracellular cytokines by flow cytometry. J Immunol Methods 1993;159:197-207.

37. Kaech SM, Tan JT, Wherry EJ, et al. Selective expression of the interleukin 7 receptor identifies effector CD8 T cells that give rise to long-lived memory cells. Nat Immunol 2003;4:1191-1198.

38. Kalia V, Sarkar S, Subramaniam S, et al. Prolonged interleukin-2Ralpha expression on virus-specific CD8+ T cells favors terminal-effector differentiation in vivo. Immunity 2010;32:91-103.

39. Kedzierska K, Stambas J, Jenkins MR, et al. Location rather than CD62L phenotype is critical in the early establishment of influenza-specific CD8+ T cell memory. Proc Natl Acad Sci U S A 2007;104:9782-9787.

40. Klose CS, Kiss EA, Schwierzeck V, et al. A T-bet gradient controls the fate and function of CCR6-RORgammat+ innate lymphoid cells. Nature 2013;494:261-265.

41. La Gruta NL, Gras S, Daley SR, et al. Understanding the drivers of MHC restriction of $\mathrm{T}$ cell receptors. Nat Rev Immunol 2018;18:467-478.

42. Lau CM, Adams NM, Geary CD, et al. Epigenetic control of innate and adaptive immune memory. Nat Immunol 2018;19:963-972.

43. Lenz LL, Dere B, and Bevan MJ. Identification of an H2M3-restricted Listeria epitope: implications for antigen presentation by M3. Immunity 1996;5:63-72.

44. Leong YA, Chen Y, Ong HS, et al. CXCR5(+) follicular cytotoxic $\mathrm{T}$ cells control viral infection in $\mathrm{B}$ cell follicles. Nat Immunol 2016;17:1187-1196.

45. Lim AI, Menegatti S, Bustamante J, et al. IL-12 drives functional plasticity of human group 2 innate lymphoid cells. J Exp Med 2016;213:569-583.

46. Lyons $\mathrm{AB}$, and Parish CR. Determination of lymphocyte division by flow cytometry. J Immunol Methods 1994;171: 131-137.

47. Maecker HT, Hassler J, Payne JK, et al. Precision and linearity targets for validation of an IFNgamma ELISPOT, cytokine flow cytometry, and tetramer assay using CMV peptides. BMC Immunol 2008;9:9.

48. Marshall DR, Turner SJ, Belz GT, et al. Measuring the diaspora for virus-specific CD8+ T cells. Proc Natl Acad Sci U S A 2001;98:6313-6318.

49. Masopust D, Vezys V, Marzo AL, et al. Preferential localization of effector memory cells in nonlymphoid tissue. Science 2001;291:2413-2417.

50. Matloubian M, Concepcion RJ, and Ahmed R. CD4+ T cells are required to sustain $\mathrm{CD} 8+$ cytotoxic $\mathrm{T}$-cell responses during chronic viral infection. J Virol 1994;68:8056-8063.

51. Metchnikoff E. Lectures on the Comparative Pathology of Inflammation [in French]. Paris: Masson, 1892. 
52. Mueller SN, Jones CM, Smith CM, et al. Rapid cytotoxic T lymphocyte activation occurs in the draining lymph nodes after cutaneous herpes simplex virus infection as a result of early antigen presentation and not the presence of virus. J Exp Med 2002;195:651-656.

53. Murali-Krishna K, Altman JD, Suresh M, et al. Counting antigen-specific CD8 T cells: a reevaluation of bystander activation during viral infection. Immunity 1998;8:177187.

54. Ohne Y, Silver JS, Thompson-Snipes L, et al. IL-1 is a critical regulator of group 2 innate lymphoid cell function and plasticity. Nat Immunol 2016;17:646-655.

55. Pamer EG, Wang CR, Flaherty L, et al. H-2M3 presents a Listeria monocytogenes peptide to cytotoxic $\mathrm{T}$ lymphocytes. Cell 1992;70:215-223.

56. Pipkin ME, Sacks JA, Cruz-Guilloty F, et al. Interleukin-2 and inflammation induce distinct transcriptional programs that promote the differentiation of effector cytolytic T cells. Immunity 2010;32:79-90.

57. Pope C, Kim SK, Marzo A, et al. Organ-specific regulation of the CD8 $\mathrm{T}$ cell response to Listeria monocytogenes infection. J Immunol 2001;166:3402-3409.

58. Quah BJ, Warren HS, and Parish CR. Monitoring lymphocyte proliferation in vitro and in vivo with the intracellular fluorescent dye carboxyfluorescein diacetate succinimidyl ester. Nat Protoc 2007;2:2049-2056.

59. Rahimpour A, Koay HF, Enders A, et al. Identification of phenotypically and functionally heterogeneous mouse mucosal-associated invariant $\mathrm{T}$ cells using MR1 tetramers. J Exp Med 2015;212:1095-1108.

60. Rankin LC, Girard-Madoux MJ, Seillet C, et al. Complementarity and redundancy of IL-22-producing innate lymphoid cells. Nat Immunol 2016;17:179-186.

61. Rankin LC, Groom JR, Chopin M, et al. The transcription factor T-bet is essential for the development of NKp46(+) innate lymphocytes via the Notch pathway. Nat Immunol 2013;14:389-395.

62. Salio M, Silk JD, Jones EY, et al. Biology of CD1- and MR1restricted T cells. Annu Rev Immunol 2014;32:323-366.

63. Sciume G, Hirahara K, Takahashi $\mathrm{H}$, et al. Distinct requirements for T-bet in gut innate lymphoid cells. J Exp Med 2012;209:2331-2338.

64. Scriba TJ, Zhang HT, Brown HL, et al. HIV-1-specific CD4+ T lymphocyte turnover and activation increase upon viral rebound. J Clin Invest 2005;115:443-450.

65. Silver JS, Kearley J, Copenhaver AM, et al. Inflammatory triggers associated with exacerbations of COPD orchestrate plasticity of group 2 innate lymphoid cells in the lungs. Nat Immunol 2016;17:626-635.

66. Snell GD. Methods for the study of histocompatibility genes. J Genet 1948;49:87-108.

67. Snell GD, Cloudman AM, and Woodworth E. Tumor immunity in mice, induced with lyophilized tissue, as influenced by tumor strain, host strain, source of tissue, and dosage. Cancer Res 1948;8:429-437.

68. Stambas J, Doherty PC, and Turner SJ. An in vivo cytotoxicity threshold for influenza A virus-specific effector and memory CD8(+) T cells. J Immunol 2007;178:1285-1292.

69. Stevenson PG, Belz GT, Altman JD, et al. Changing patterns of dominance in the $\mathrm{CD} 8+\mathrm{T}$ cell response during acute and persistent murine gamma-herpesvirus infection. Eur J Immunol 1999;29:1059-1067.

70. Sun JC, Beilke JN, and Lanier LL. Adaptive immune features of natural killer cells. Nature 2009;457:557-561.

71. Sun JC, Williams MA, and Bevan MJ. CD4+ T cells are required for the maintenance, not programming, of memory CD8+ T cells after acute infection. Nat Immunol 2004;5: 927-933.

72. Suni MA, Picker LJ, and Maino VC. Detection of antigenspecific $\mathrm{T}$ cell cytokine expression in whole blood by flow cytometry. J Immunol Methods 1998;212:89-98.

73. Swain SL, Panfili PR, Dutton RW, et al. Frequency of allogeneic helper $\mathrm{T}$ cells responding to whole $\mathrm{H}-2$ differences and to an H-2K difference alone. J Immunol 1979;123: 1062-1067.

74. Thomas PG, Handel A, Doherty PC, et al. Ecological analysis of antigen-specific CTL repertoires defines the relationship between naive and immune T-cell populations. Proc Natl Acad Sci U S A 2013;110:1839-1844.

75. Treiner E, Duban L, Bahram S, et al. Selection of evolutionarily conserved mucosal-associated invariant $\mathrm{T}$ cells by MR1. Nature 2003;422:164-169.

76. van der Most RG, Murali-Krishna $\mathrm{K}$, Lanier JG, et al. Changing immunodominance patterns in antiviral CD8 Tcell responses after loss of epitope presentation or chronic antigenic stimulation. Virology 2003;315:93-102.

77. Vivier E, van de Pavert SA, Cooper MD, et al. The evolution of innate lymphoid cells. Nat Immunol 2016;17:790794.

78. Vonarbourg C, Mortha A, Bui VL, et al. Regulated expression of nuclear receptor RORgammat confers distinct functional fates to NK cell receptor-expressing RORgammat(+) innate lymphocytes. Immunity 2010;33:736751.

79. Wysocka M, Eisenlohr LC, Otvos L, Jr., et al. Identification of overlapping class I and class II H-2d-restricted $\mathrm{T}$ cell determinants of influenza virus $\mathrm{N} 1$ neuraminidase that require infectious virus for presentation. Virology 1994;201: 86-94.

80. Youngblood B, Hale JS, Kissick HT, et al. Effector CD8 T cells dedifferentiate into long-lived memory cells. Nature 2017;552:404-409.

81. Zinkernagel RM, and Doherty PC. Immunological surveillance against altered self components by sensitised $\mathrm{T}$ lymphocytes in lymphocytic choriomeningitis. Nature 1974; 251:547-548.

82. Zinkernagel RM, and Doherty PC. Restriction of in vitro T cell-mediated cytotoxicity in lymphocytic choriomeningitis within a syngeneic or semiallogeneic system. Nature 1974; 248:701-702.

Address correspondence to: Prof. Gabrielle T. Belz

The University of Queensland Diamantina Institute 37 Kent Street Woolloongabba Qld 4102 Australia

E-mail: g.belz@uq.edu.au 